\title{
Down-regulation of ghrelin receptors on dopaminergic neurons in the substantia nigra contributes to Parkinson's disease-like motor dysfunction
}

\author{
Yukari Suda ${ }^{1 \dagger}$, Naoko Kuzumaki ${ }^{1,2^{*}}$, Takefumi Sone ${ }^{2}$, Michiko Narita ${ }^{1}$, Kenichi Tanaka ${ }^{1}$, Yusuke Hamada ${ }^{1}$, \\ Chizuru Iwasawa ${ }^{1}$, Masahiro Shibasaki ${ }^{1}$, Aya Maekawa ${ }^{3}$, Miri Matsuo', Wado Akamatsu ${ }^{2,4}$, Nobutaka Hattori ${ }^{5}$, \\ Hideyuki Okano ${ }^{2,6^{*}}$ and Minoru Narita ${ }^{1,6^{*}}$
}

\begin{abstract}
Ghrelin exerts a wide range of physiological actions throughout the body and appears to be a promising target for disease therapy. Endogenous ghrelin receptors (GHSRs) are present in extrahypothalamic sites including the substantia nigra pars compacta (SNc), which is related to phenotypic dysregulation or frank degeneration in Parkinson's disease (PD). Here we found a dramatic decrease in the expression of GHSR in PD-specific induced pluripotent stem cell (iPSC)-derived dopaminergic (DAnergic) neurons generated from patients carrying parkin gene (PARK2) mutations compared to those from healthy controls. Consistently, a significant decrease in the expression of GHSR was found in DAnergic neurons of isogenic PARK2-iPSC lines that mimicked loss of function of the PARK2 gene through CRISPR Cas9 technology. Furthermore, either intracerebroventricular injection or microinjection into the SNc of the selective GHSR1a antagonist [D-Lys3]-GHRP6 in normal mice produced cataleptic behaviors related to dysfunction of motor coordination. These findings suggest that the down-regulation of GHSRs in SNc-DA neurons induced the initial dysfunction of DA neurons, leading to extrapyramidal disorder under PD.
\end{abstract}

Keywords: Parkinson's disease, Ghrelin, GHSR, iPS, Dopamine neuron

\section{Introduction}

Parkinson's disease (PD) is a common, debilitating, neurodegenerative disorder that is associated with progressive motor dysfunction. PD is characterized by the progressive loss of dopamine (DA) neurons, and the DA neurons that degenerate in PD primarily project to the substantia nigra pars compacta $(\mathrm{SNc})$. The motor symptoms of PD manifest only after a significant loss of striatal $(70-80 \%)$ DA concentration in the brain and are seen relatively late in disease progression. PARKIN (PARK2), an E3 ubiquitin ligase, is the most frequently

\footnotetext{
*Correspondence: n-kuzumaki@hoshi.ac.jp; hidokano@a2.keio.jp; narita@hoshi.ac.jp

tEqual contributors

${ }^{1}$ Department of Pharmacology, Hoshi University School of Pharmacy and Pharmaceutical Sciences, Ebara, Shinagawa-ku, Tokyo 142-8501, Japan

${ }^{2}$ Department of Physiology, Keio University School of Medicine, 35

Shinanomachi, Shinjuku-ku, Tokyo 160-8582, Japan

Full list of author information is available at the end of the article
}

mutated gene that has been causally linked to autosomal recessive early-onset familial Parkinson's disease $[1,2]$. Abnormalities of PARK2 have also been described in sporadic PD [3].

Induced pluripotent stem cells (iPSCs) give rise to all cells in an organism. A potential solution to the difficulty of modeling PD is to use reprogramming technology to generate disease-specific iPSCs. PD-specific iPSCs-derived DA neurons could recapitulate the pathological features of PD. The exact mechanism by which PARK2 causes PD-like syndromes and why dopaminergic neurons are primarily affected by a ubiquitously expressed mutation remain unknown [4, 5]. A monogenic form of PD-specific iPSCs-derived DA neurons could provide important clues for elucidating the pathogenesis of PD.

Ghrelin, an endogenous ligand for growth hormone secretagogue receptor (GHSR), which is classified as a 
G-protein coupled receptor, is a 28 -amino acid peptide that regulates growth hormone secretion, food intake, reward-seeking behavior and memory performance [6-9]. While it is mainly secreted from the stomach [8], small amounts are produced in the brain [10]. GHSR is expressed in various brain areas including the SNc, hypothalamus, ventral tegmental area and hippocampus, where ghrelin directly modulates neuronal activity $[6,7,11,12]$. In the SNc, ghrelin electrically activates dopaminergic neurons, and increases the dopamine concentration in the striatum via the specific blockade of KCNQ channel function [13]. It has also been reported that ghrelin has a neuroprotective effect to prevent the greater loss of SNc dopaminergic neurons in a 1-methyl-4-phenyl-1,2,3,6-tetrahydropyridine (MPTP) model of PD [11].

In the present study, we evaluated the changes in GHSR expression in dopaminergic neurons derived from PD-specific iPS cells. Furthermore, we confirmed that the inhibition of GHSR in DA neurons of the substantia nigra, using the microinjection of a selective GHSR inhibitor into the SNc, leads to motor dysfunction.

\section{Methods}

Human iPS cells

For control lines, we used two human iPS cell lines: 201B7 iPSCs were purchased from RIKEN BRC and kindly provided by Dr. Shinya Yamanaka [14] at Kyoto University and WD39 iPSCs were established [15] at Keio University. For PD (PARK2) lines, the patient A (PA9 and PA22) and patient B (PB2 and PB20) iPSCs were established by Dr. Imaizumi [15]. All of the iPSCs were maintained on feeder cells in iPSC culture media, as described previously [15]. All of the experimental procedures for iPS cell production were approved by the Ethics Committee of Keio University School of Medicine. All of the experimental procedures for cell differentiation and analysis were approved by the respective Ethics Committees of Keio University School of Medicine (Approval Number: 20-16-28) and Hoshi University School of Medicine (Approval Number: 28-008).

\section{In vitro differentiation of human iPSCs (hiPSCs)}

DA neuron differentiation from iPSCs was performed according to a previously reported protocol [16-18]. Neural induction was initiated through the inhibition of both BMP and TGF $\beta$ signaling using the small molecules Dorsomorphin (DM, Sigma-Aldrich, St. Louis, MO, USA) and SB431542 (SB, Tocris Bioscience, Bristol, UK). The small molecule CHIR99021 (CHIR, Stemgent, Lexington, MA, USA), a GSK3 $\beta$ inhibitor, was added to stimulate the canonical WNT signaling pathway. For neural induction from single hiPSCs, hiPSCs were incubated with TrypLE ${ }^{\text {тs }}$ Select (Gibco, Life Technologies, CA, USA) for 5-10 min and dissociated into single cells by pipetting. Cells were plated into a T75 flask and cultured in KBM (KOHJINBIO, Saitama, Japan) supplemented with B27 (Gibco, Life Technologies), 20 ng/mL basic-FGF (bFGF, PeproTech. Inc., Rocky Hill, NJ, USA), $10 \mu \mathrm{M}$ Y-27632 (Wako, Tokyo, Japan), 10 ng/mL hLIF (Millipore, Billerica, MA, USA), $1 \mu \mathrm{M}$ Purmorphamine (Calbiochem, San Diego, CA, USA), $2 \mu \mathrm{M}$ SB (Tocris Bioscience), 100 ng/ml CHIR, 100 ng/ml Sonic hedgehog (Shh, R\&D Systems Inc., Minneapolis, MN, USA) and $100 \mathrm{ng} / \mathrm{ml} \mathrm{FGF8b}$ (PeproTech) in 4\% oxygen for 7 or 12 days. Neurospheres were repeatedly passaged by dissociation into single cells, and then cultured in the same manner. Neurospheres at passage 3 were typically used for analysis. For terminal differentiation, dissociated neurospheres were allowed to adhere to poly-L-ornithine (Sigma-Aldrich)- and fibronectin (Sigma-Aldrich)-coated coverslips and cultured in KBM (KOHJINBIO) containing B27 (Gibco, Life Technologies), $20 \mathrm{ng} / \mathrm{mL}$ brain-derived neurotrophic factor (BDNF, R\&D Systems), $20 \mathrm{ng} / \mathrm{mL}$ glial cell-derived neurotrophic factor (GDNF, R\&D Systems), $200 \mu \mathrm{M}$ ascorbic acid (Sigma-Aldrich), and $500 \mu \mathrm{M}$ dibutyryl-cAMP (Sigma-Aldrich) for 10 days.

\section{Immunocytochemical analysis}

Cells were fixed with $4 \%$ paraformaldehyde (PFA) and then washed three times with PBS. After cells were incubated with blocking buffer (PBS containing 5\% normal fetal bovine serum and $0.3 \%$ Triton $\mathrm{X}-100$ ) for $1 \mathrm{~h}$ at room temperature, they were incubated overnight at $4{ }^{\circ} \mathrm{C}$ with primary antibodies diluted with blocking buffer. The details of the primary antibodies and the dilution conditions are listed in Additional file 1: Table S1. The cells were again washed three times with PBS and incubated with secondary antibodies conjugated with Alexa Fluor 488 or Alexa Fluor 546 for $1 \mathrm{~h}$ at room temperature. After cells were washed three times with PBS, samples were mounted on slides with DAPI-Fluoromount-G ${ }^{\mathrm{rm}}$ (SouthernBiotech, Birmingham, AL, USA). Fluorescence of immunolabeling was detected using a light microscope BZ-X710 (KEYENCE, Osaka, Japan) or IX-73 (Olympus, Tokyo, Japan) and photographed with a digital camera using BZ-X Analyze software (KEYENCE) or cellSens software (Olympus).

\section{qRT-PCR}

Total RNA was isolated from cells using an RNeasy mini kit (QIAGEN, Hilden, Germany) with DNase I treatment, and cDNA was prepared by using a SuperScript ${ }^{\circ}$ VILO $^{\text {ma }}$ cDNA Synthesis Kit (Invitrogen, Waltham, MA, USA). The qRT-PCR analysis was performed with Fast SYBR Green Master Mix (Thermo Fisher Scientific, Waltham, MA, USA) on a StepOne Plus ${ }^{\text {тм }}$ System (Applied Biosystems Inc., Foster City, CA, USA). Values were normalized to $\beta$ actin (ACTB). The 
primer sets used in these experiments are listed in Additional file 2: Table S2.

\section{Generation of PARK2 gene knock-in/knock-out (PARK2- KIKO line) by CRISPR-Cas9}

We previously generated CRISPR/Cas9-dependent PARK2-KIKO line using 201B7 as control iPSCs, to evaluate parkin loss of function on DA neurons-derived from iPSCs (Kuzumaki et al., in submission). In brief, a targeting donor DNA plasmid (pUC- 5'3'PARK2- PurTK) was used to disrupt exon 2 of $P A R K 2$ gene by homologous recombination. The CSIV-U6-PARK2 (Ex2)-sgRNA-L\&REF-Csy4-2A-Cas9 was used as a house-made all-in-one vector. The 201B7 was suspended in Opti-MEM (Thermo Fisher) containing Y-27632, house-made all-in-one vector and targeting donor DNA vector plasmid. Electroporation of plasmid DNA was performed using a NEPA21 electroporator (Nepa Gene Co., Ichikawa, Japan). As shown in Additional file 3: Figure S1, PARK2-KIKO clone was identified by PCR method with the primers listed in Additional file 4: Table S3.

\section{Animals}

The present study was conducted in accordance with the Guiding Principles for the Care and Use of Laboratory Animals, Hoshi University, as adopted by the Committee on Animal Research of Hoshi University, which is accredited by the Animal Research Committee of Hoshi University. Male C57BL/6 J mice (Jackson Laboratory) were used in this study. All mice were housed at up to 6 mice per cage and kept in a temperature-controlled room $\left(24 \pm 1{ }^{\circ} \mathrm{C}\right)$ maintained on a $12 \mathrm{~h}$ light-dark cycle (light on at 8 a.m.). Food and water were available ad libitum.

\section{Drugs}

[D-Lys-3]-GHRP-6 (Tocris, Bristol, United Kingdom) and morphine hydrochloride (Daiichi-Sankyo Co., Ltd., Tokyo, Japan) were used in this study.

\section{Intracerebroventricular administration}

Intracerebroventricular (i.c.v.) administration was performed according to the method described previously [19]. A $2 \mathrm{~mm}$ double needle (Natsume Seisakusho) attached to a $25 \mu \mathrm{l}$ Hamilton microsyringe was inserted into the unilateral injection site using a V-shaped holder to hold the head of the mouse. On the day of the assay, [D-Lys-3]-GHRP-6 (0.3 to $10 \mathrm{nmol} /$ mouse) was injected into the hole. The injection volume was $4 \mu \mathrm{l}$ for each mouse.

\section{Cannula implantation into the SNc}

Stereotaxic injections were performed under isoflurane (3\%) anesthesia and using small-animal stereotaxic instruments (RWD Life Science, Shenzhen, China). Mice were placed in a stereotaxic apparatus and the skull was exposed. A small hole was then made in the skull using a dental drill. A guide cannula (EIM-54; Eicom, San Diego, CA, USA) was implanted into the SNc (from bregma: AP $-3.0 \mathrm{~mm}, \mathrm{ML} \pm 1.2 \mathrm{~mm}$, DV $-4.3 \mathrm{~mm}$ ). [D-Lys-3]-GHRP-6 (1 to $5 \mathrm{nmol} /$ side) was microinjected at a rate of $0.25 \mu \mathrm{min}^{-1}$ for $4 \mathrm{~min}$. At the end of injection, the injection cannula was kept in the SNc for an additional $2 \mathrm{~min}$ before removal and then replaced by a stylet.

\section{Rotarod assay test}

Motor coordination was assessed using the rotarod test. Mice were individually placed on a slowly rotating rod (4 $\mathrm{rpm} / \mathrm{min}$ ), and subjected to continuous acceleration at $20 \mathrm{rpm} / \mathrm{min}$; the time at which the mouse fell off the rod was recorded. The test was performed $10 \mathrm{~min}$ after i.c.v. injection of either saline vehicle or [D-Lys-3]GHRP-6 (0.3 to $10 \mathrm{nmol} / \mathrm{mouse})$, or $15 \mathrm{~min}$ after microinjection of either saline vehicle or [D-Lys-3]-GHRP-6 (1 to $5 \mathrm{nmol} /$ side).

\section{Balance beam test}

The apparatus consisted of a $1 \mathrm{~m}$-long bar (28 or $11 \mathrm{~mm}$ in diameter) with a black escape box on one end (O'HARA \& Co., LTD., Tokyo, Japan). Mice were acclimated to enter the escape box on the $28 \mathrm{~mm}$-diameter bar for 2 days before testing. The latency to reach the box on the $11 \mathrm{~mm}$-diameter bar was measured (cut off time $=60 \mathrm{~s}$ ). The test was performed $10 \mathrm{~min}$ after microinjection of either saline vehicle or [D-Lys-3]-GHRP-6 (1 to $5 \mathrm{nmol} /$ side).

\section{Locomotor assay}

After $30 \mathrm{~min}$ of habituation to the apparatus, the locomotor activity of mice was measured by a Three-point Meter (O'HARA \& Co., LTD). With this device, the position of the mouse is detected when the infrared beams positioned along the $\mathrm{X}$ and $\mathrm{Y}$ axes around the cage are interrupted. This device detects the movement of the whole body of the target animal, without being misled by the movement of the tail or any other part of the mouse. Counts of hyperlocomotor activity were obtained at 1-min intervals for $120 \mathrm{~min}$ after the injection of morphine hydrochloride (Daiichi-Sankyo Co., Ltd., Tokyo, Japan).

\section{Statistics}

The data are presented as the mean \pm S.E.M. The statistical significance of differences between groups was assessed by an unpaired t-test or one-way analysis of variance (ANOVA) test followed by the Bonferroni's multiple comparison test. All statistical analyses were 
performed with GraphPad Prism (GraphPad Software, La Jolla, CA, USA). A $p$ value of $<0.05$ was considered to reflect significance.

\section{Results}

Differentiation of PARK2-specific iPSCs into DA neurons

Since PD is defined pathologically by the progressive degeneration of DA neurons, we modified the method used to generate a DA neuron-enriched culture by treating iPSC-derived cells with several small molecules that lead to the formation of ventral midbrain cells, including DA neurons (Fig. 1a). Most of the differentiated cells derived from control and PARK2-specific iPSCs were labeled by antibodies to BIII-tubulin (a neuron-specific marker) and $\mathrm{TH}$ (a dopaminergic neuronal marker) (Fig. 1b). There was no significant difference in the ratio of $\mathrm{TH}$-positive DA neurons between control and PARK2 iPSCs-derived neurons (Fig. 1c). In the previous study, we demonstrated that this iPSC-based model of PARK2 recapitulated the vulnerability of DA neurons $[16,20]$.

\section{Decreased expression of GHSR in PARK2-specific iPSC-derived} DA neurons

We observed a significant decrease in mRNA levels of GHSR1a and GHSR1b in PARK2-specific iPSC-derived DA neurons (Fig. 2a-b, ${ }^{* *} p<0.01$, "*** $p<0.001$ vs.
control-iPSC derived DA neurons). Furthermore, the protein levels of GHSR were mostly abolished in DA neurons-derived from PARK2-specific iPSCs (Fig. 2c).

\section{Recapitulation of GHSR expression in isogenic PARK2- KIKO iPSC-derived DA neurons}

We next used isogenic iPSC lines mimicking loss of function of the PARK2 gene through CRISPR Cas9 technology in the healthy control iPSC line 201B7 (Fig. 3a). We found that one of the PARK2-KIKO iPSC lines, B7PA21 differentiated to TH-positive neurons (Fig. 3b). We confirmed the knock-down of Parkin mRNA in DA neurons-derived from PARK2-KIKO isogenic iPSCs (Fig. 3c). Under these conditions, we found a significant decrease in the mRNA expression of GHSR1a and GHSR1b in the PARK2-KIKO isogenic line, similar to that seen in the familial PARK2 lines (Fig. 3d-e).

\section{Effects of intracerebroventricular injection of the selective} GHSR1a antagonist [D-Lys3]-GHRP-6 on motor coordination To evaluate the in vivo effect of the blockade of central GHSR1a, normal mice were subjected to intracerebroventricular (i.c.v.) injection of the selective GHSR1a antagonist [D-Lys3]-GHRP-6 (0.3 to $10 \mathrm{nmol} /$ mouse). The i.c.v. injection of [D-Lys3]-GHRP-6 in
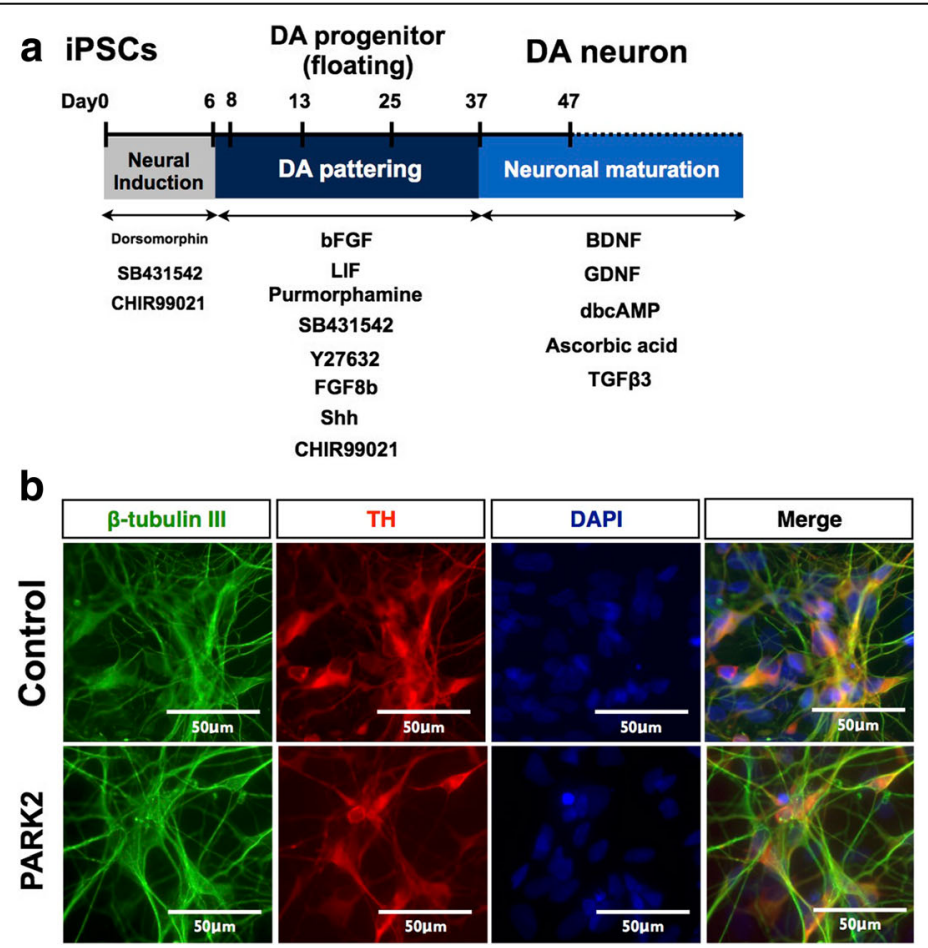

C

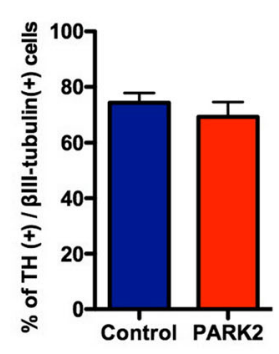

Fig. 1 Ghrelin receptor (GHSR) expression in dopaminergic neurons derived from control and PARK2-specific iPSCs. a Schematic of the induction of a DA-enriched culture protocol. b Double-labeling for the dopaminergic neuron marker tyrosine hydroxylase (TH, red) and neurons ( $\beta$ III-tubulin, green) of control and PARK2-specific iPSC-derived dopaminergic neurons. Scale bar $=50 \mu \mathrm{m}$. c Quantitative data of the percentage of TH positive cells per $\beta$ III-tubulin positive cells 

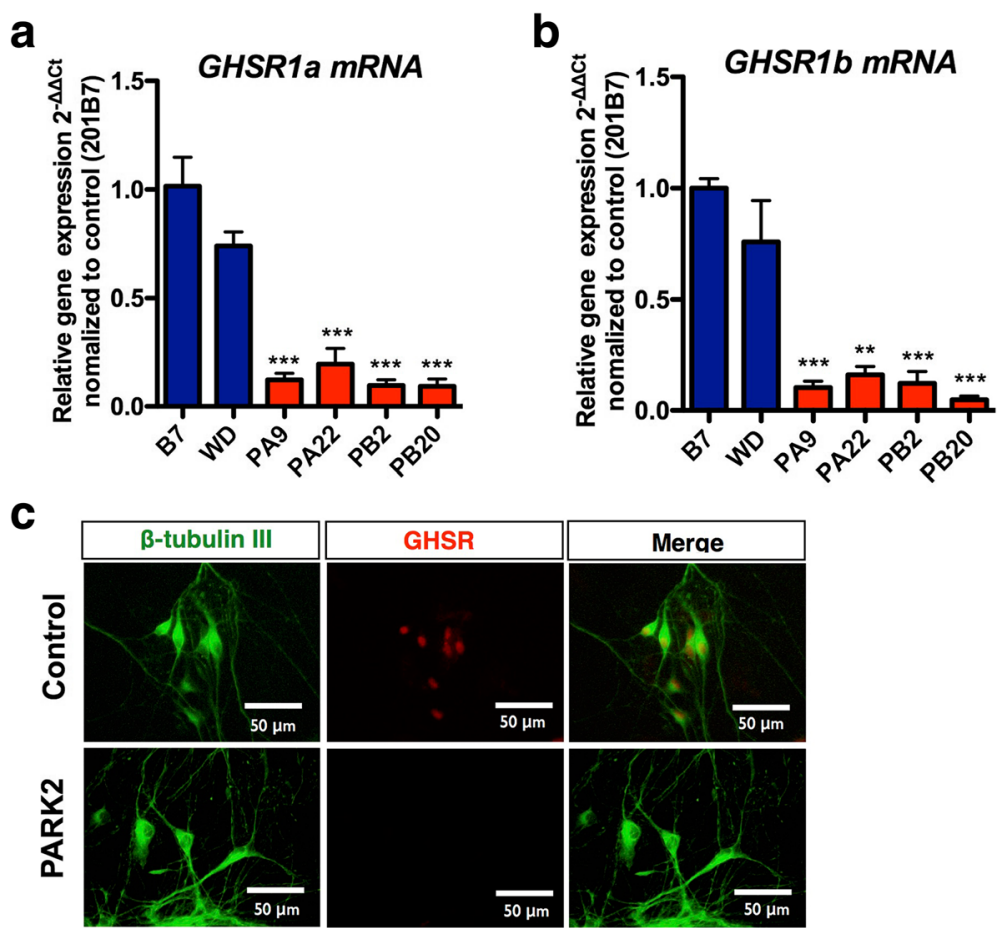

Fig. 2 Ghrelin receptor (GHSR) expression in dopaminergic neurons derived from control and PARK2-specific iPSCs. a-b mRNA expression of GHSR1a (a) and GHSR1b (b) between control and Parkinson's disease-specific iPS cells derived-dopaminergic neurons. ${ }^{* *} p<0.01,{ }^{* * *} p<0.001$ vs. control iPS cell-derived dopaminergic neurons. c Immunocytochemical analysis for TH (green) and ghrelin receptor (red) in control and PARK2 iPS cell-derived dopaminergic neurons

mice induced a dose-dependent impairment of motor coordination based on the rota-rod performance test (Fig. 4a). [D-Lys3]-GHRP-6 given i.c.v. at $0.3 \mathrm{nmol}$, which alone had no effect on motor coordination, significantly inhibited morphine-induced hyperlocomotion (Fig. $4 \mathrm{~b}-\mathrm{c},{ }^{*} p<0.05$ vs. SAL-MRP5).

\section{Effects of intra-SNc injection of [D-Lys3]-GHRP-6 on motor coordination}

To evaluate the in vivo effect of the blockade of GHSR1a, a guide cannula was implanted into the SNc for microinjection (Fig. 5a). One day after cannula implantation (Fig. 5b), microinjection of [D-Lys3]-GHRP-6 ( 1 to $5 \mathrm{nmol} / \mathrm{side}$ ) into the $\mathrm{SNc}$ of normal mice produced a significant and dose-dependent impairment of motor coordination in the rota-rod test (Fig. $5 \mathrm{c},{ }^{*} p<$ 0.05 vs. saline). In the balance beam test to further evaluate catalepsy behaviors, microinjection of [D-Lys3]GHRP-6 into the SNc significantly increased the latency to cross the beam and increased the number of mice that fell from the beam (Fig. $5 \mathrm{~d}-\mathrm{e},{ }^{* * * *} p<0.001$ vs. saline). These results suggest that the blockade of GHSR activation on DA neurons of the $\mathrm{SNc}$ induced motor dysfunction.

\section{Discussion}

The identification of cell biological or biochemical changes in the initial stages of Parkinson's disease, before the onset of symptoms, has been difficult through the use of analyses conducted on postmortem brains. With the recent development of iPS cell technologies, it has become possible to establish pluripotent stem cells from the somatic cells of anyone, regardless of race, genetic background, or the presence of disease symptoms. We have established iPS cells from cutaneous fibroblasts obtained from patients with the PARK2 form of familial PD (Patient A: female with an exon 2-4 deletion mutation; Patient B: male with an exon 6-7 deletion mutation) by performing retroviral gene transduction (Oct4, Sox2, Klf4, and $c-M y c)[15,21]$. In the previous study, we demonstrated that this iPSC-based model of PARK2 recapitulated the vulnerability of DA neurons with a significant increase in ROS production $[16,20]$. In our preliminary DNA microarray study, a dramatic decrease in mRNA levels of GHSR1a and GHSR $1 b$ was found in PARK2-specific iPSC-derived DA neurons (unpublished observation). In the present q-PCR assay, we confirmed that a significant decrease in both mRNAs was detected compared to a control in PARK2-specific iPSC-derived DA neurons. Furthermore, 


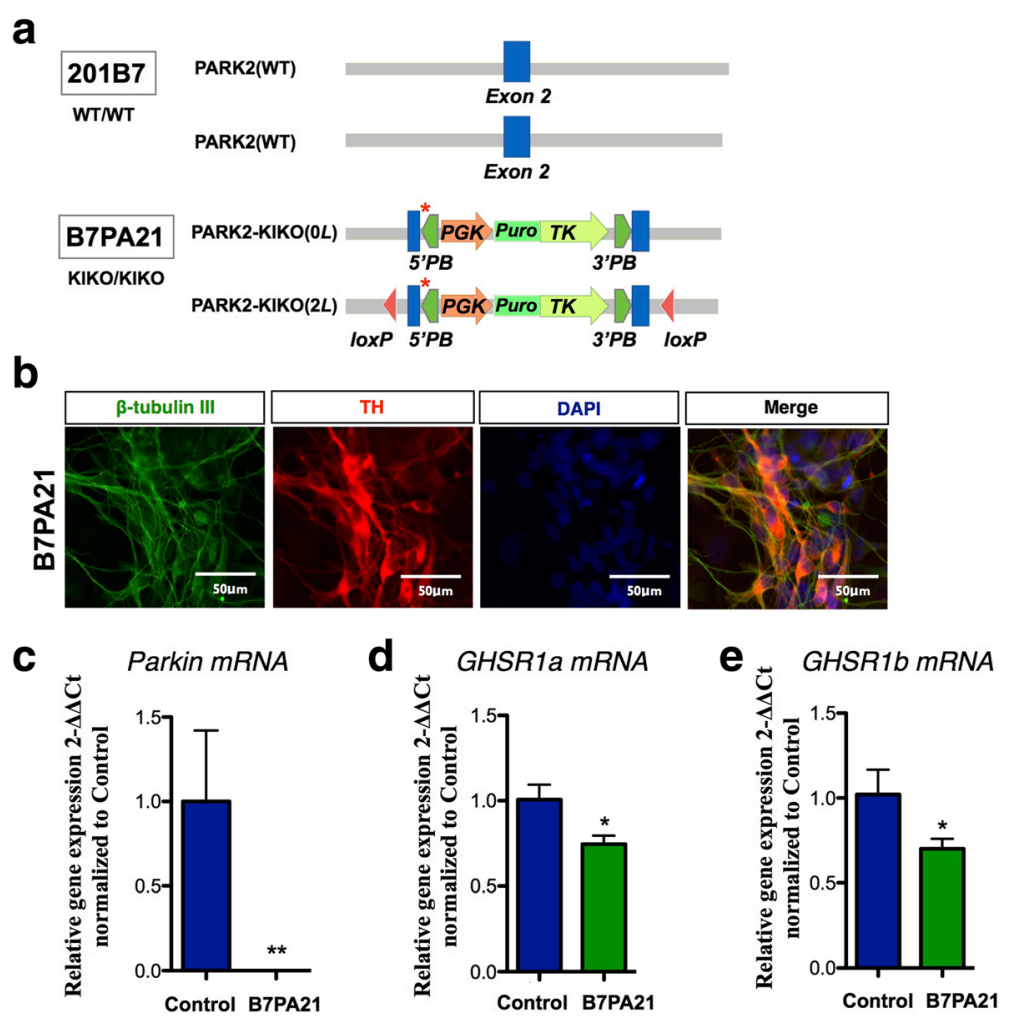

Fig. 3 Decreased expression of GHSR in isogenic PARK2-KIKO IPSC-derived DA neurons. a Generation of isogenic PARK2-KIKO iPSCs. Schematic illustration of the gene-editing strategy for knock-in of the stop codon and the puromycin resistance gene into control iPSCs (201B7). b Double-labeling for the DA neuron marker tyrosine hydroxylase (TH, red) and the neuronal marker $\beta$-tubulin III (TUJ1, green) of control and PARK2-KIKO iPSC-derived dopaminergic neurons. $\mathbf{c}$ Expression level of Parkin mRNA in differentiated DA neurons derived from the control and PARK2- KIKO iPSC groups. ${ }^{* *} p<0.01$ vs. control. d-e The expression levels of GHSR1a (d) and GHSR1b (e) in differentiated dopaminergic neurons derived from the control and PARK2-KIKO iPSC groups. ${ }^{*} p<0.05$ vs. control

the level of GHSR protein was clearly down-regulated in DA neurons in PARK2-specific iPSC-derived DA neurons. To evaluate whether PARK2 mutation is sufficient to cause the observed phenotype, we generated isogenic iPSC lines mimicking loss of function of the PARK2 gene in a healthy control iPSC line. Under these conditions, we consistently found the significant, but not dramatic, decrease in the mRNA expression of both GHSR1a and GHSR1b in the PARK2-KIKO isogenic line. Although further analyses will be required to identify how PARK2 mutation could affect the expression of GHSR1a, PARK2 mutation may lead to the possible changes in the transfer of ubiquitin onto substrate proteins, which could affect the transcriptional level of GHSR1a. We thus hypothesized that although the deletion of PARK2 gene would, at least in part, contribute to the decrease in the mRNA expression of both GHSR1a and GHSR1b, PARK2-specific iPSC-derived DA neurons from patients could be influenced by another genomic mutant factors to induce the dramatic knockdown of both mRNAs.
GHSR1a is the only functional ghrelin receptor that has been characterized to date. It is a G protein-coupled 7 -transmembrane receptor that was first cloned from the pituitary and hypothalamus [22]. It has been reported that GHSR1a is localized in dopaminergic neurons of the SNc [23]. Higher numbers of TH and GHSR co-expressing neurons have been identified within the substantia nigra pars compacta [23]. Ghrelin has been shown to have neuroprotective effects in numerous animal models of neurological disorders, including PD. Studies using the mitochondrial toxin MPTP, which selectively kills dopaminergic neurons in the SNc, have shown that i.p. injection of ghrelin restricts dopamine cell loss in the SNc and the loss of dopamine in the striatum in mice [11, 24, 25]. Ghrelin activates SNc dopaminergic neurons, increases the expression of tyrosine hydroxylase (which is involved in the biosynthesis of dopamine) in the midbrain, and increases dopamine turnover in the dorsal striatum [11]. In the present study, we investigated whether the direct inhibition of GHSR function in the brain including the $\mathrm{SNc}$ could affect motor coordination. Either i.c.v. or intra-SNc 
a

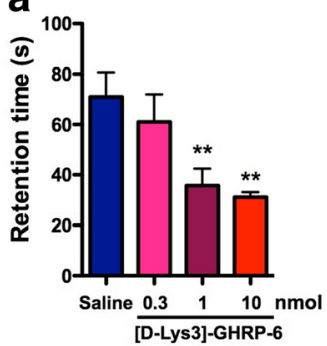

b

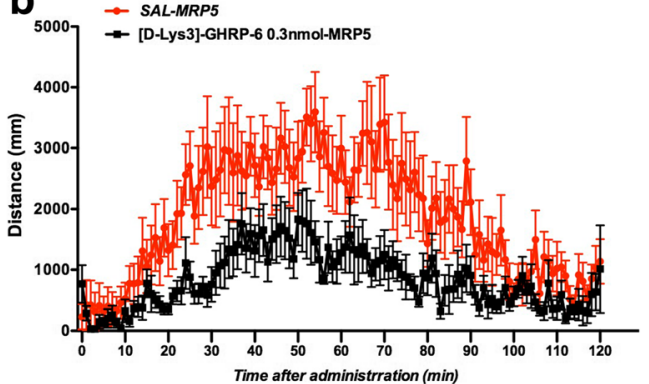

C
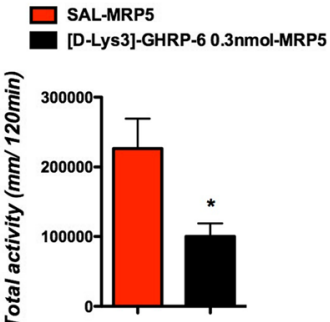

Fig. 4 Effects of intracerebroventricular injection of the selective GHSR1a antagonist [D-Lys3]-GHRP-6 on motor coordination. a Average latency to fall in the rotarod test. ${ }^{* *} p<0.01$ vs. SAL. b Time-course change in the locomotor-enhancing effect of morphine $(5 \mathrm{mg} / \mathrm{kg}$, s.c.) after treatment with [D-Lys3]-GHRP-6 at $0.3 \mathrm{nmol}(n=7)$ or saline $(n=8)$. Each point represents the mean activity distance for 1 min with SEM. c Total locomotor activity induced by morphine ( $5 \mathrm{mg} / \mathrm{kg}$, s.c.) after treatment with [D-Lys3]-GHRP- 6 at $0.3 \mathrm{nmol}(n=7)$ or saline $(n=8)$. Each column represents the mean total activity distance for 120 min with SEM. ${ }^{*} p<0.05$ vs. SAL-MRP5

injection of the selective GHSR1a antagonist [D-Lys3]GHRP-6 in normal mice induced dose-dependent cataleptic behaviors related to the dysfunction of motor coordination. Furthermore, [D-Lys3]-GHRP-6, given i.c.v. at a dose which alone had no effect on motor coordination, caused a significant inhibition of the dopamine-related hyperlocomotion induced by the systemic administration of morphine. These findings suggest that deficits in GHSR activity in SNc-dopamine neurons could cause marked motor impairment. Inconsistently, it has been reported that $\mathrm{GHSR}^{-/-}$mice did not show reduced performance in the rotarod test [26].
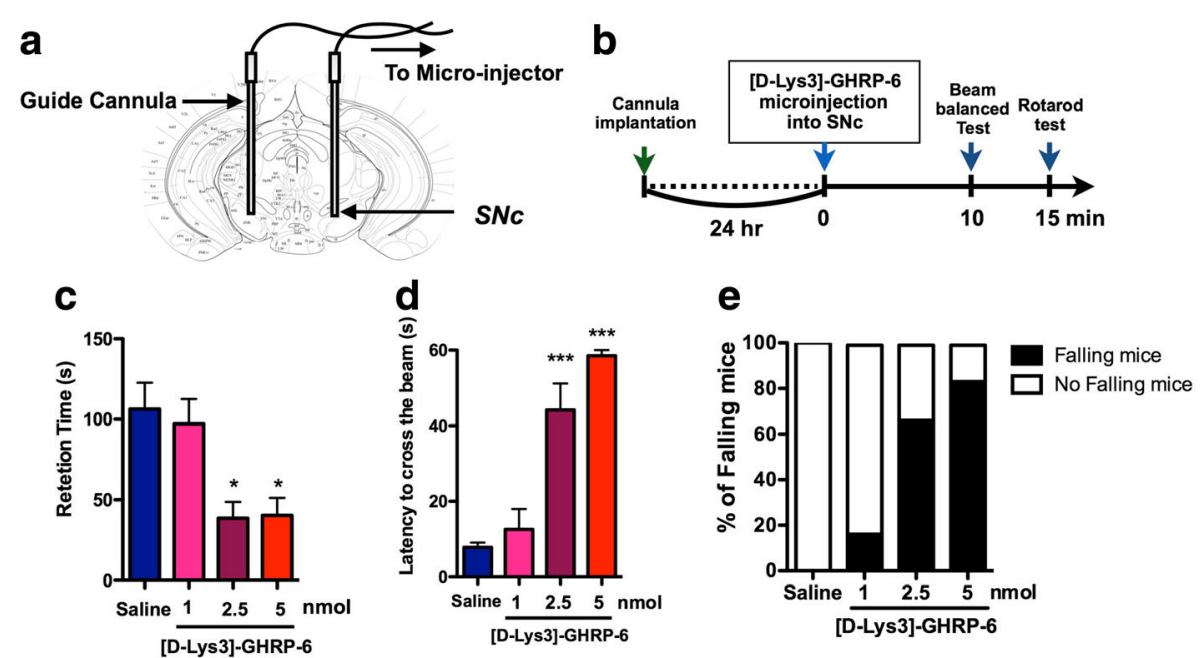

Fig. 5 Effects of intra-SNc injection of [D-Lys3]-GHRP-6 on motor coordination. a Microinjection sites of [D-Lys3]-GHRP-6 in the SNc. Plates show coronal sections of the mouse brain. $\mathbf{b}$ Schedule for the experiment. $\mathbf{c}$ Accelerated rotarod test (4-20 rpm). The line graph shows the average latency to fall in the rotarod test for $15 \mathrm{~min}$ after bilateral microinjection of [D-Lys3]-GHRP-6 (1, $2.5 \mathrm{or} 5 \mathrm{nmol} /$ each site) or saline $(n=6 / \mathrm{group})$ into the SNc. ${ }^{*} p<0.05$ vs. Saline. $\mathbf{d}$-e The balance beam test was performed $10 \mathrm{~min}$ after the microinjection of [D-Lys3]-GHRP-6 (1, 2.5 or $5 \mathrm{nmol} /$ each site) or saline ( $n=6 /$ group) into the SNc. ${ }^{* *} p<0.001$ vs. Saline 
One reason for this discrepancy may be the possibility of significant compensation in the dopaminergic system when genes are deleted or overexpressed in the germline and during development of the dopaminergic system. In fact, germline deletion of parkin fails to lead to the loss of dopaminergic neurons, whereas adult conditional knockout of parkin leads to a progressive loss of dopamine neurons $[27,28]$. Thus, it is likely that a conditional knockout technique in adults will be required to evaluate DA-related behaviors under PD.

In conclusion, we found that the expression level of GHSR was dramatically decreased in DA neurons under PD using disease-specific iPSCs. Furthermore, treatment by the injection of a selective GHSR1a inhibitor into the SNc of normal mice induced Parkinson's disease-like behaviors. Taken together, these results indicate that the down-regulation of GHSR in DA neurons may correspond to the initial dysfunction of DA neurons, leading to extrapyramidal disorder under PD.

\section{Additional files}

\section{Additional file 1: Table S1. List of antibodies used for}

immunocytochemical analysis. (JPEG 244 kb)

Additional file 2: Table S2. List of primers used for GRT-PCR analysis. (JPEG $308 \mathrm{~kb}$ )

Additional file 3: Figure S1. Detection of a selection marker cassette knock-in by PCR. Genotyping by PCR was performed by using the primers listed in Table S3. For the detection of alleles of wildtype or indels, 5'PARK2-PCR-Fw and 3'PARK2-PCR-RV, PARK2-Exon2-PCR-Fw and PARK2Exon2-PCR-Rv were used. A large 5082-bp and 3464-bp fragment derived from knock-in allele is also detectable in this primer set. For the detection of alleles of knock-in, 5'PARK2-PCR-Fw and PGKp-Rv for detection of the 5' knock-in fragment, and PuroR-Fw and 3'PARK2-PCR-Rv for detection of the 3 'knock-in fragment were used. (JPEG $429 \mathrm{~kb}$ )

Additional file 4: Table S3. List of primers used for PCR analysis. (JPEG $291 \mathrm{~kb}$ )

\section{Abbreviations}

BDNF: Brain-derived neurotrophic factor; DA: Dopamine;

DAnergic: dopaminergic; DM: Dorsomorphin; GDNF: Glial cell-derived neurotrophic factor; GHSR: Growth hormone secretagogue receptor; iPSC: Induced pluripotent stem cell; PD: Parkinson's disease; PFA: Paraformaldehyde;

SNc: Substantia nigra pars compacta

\section{Acknowledgements}

We thank Dr. Yoichi Imaizumi (Keio University) for providing PARK2-specific iPS cells; Dr. Shinya Yamanaka (Kyoto University) for providing 201B7 iPS cells.

\section{Funding}

This work was supported by Japan Society for the Promotion of Science (JSPS) KAKENHI Grant Numbers JP16K08280 to N.K. This work was also supported by the Project for the Realization of Regenerative Medicine and Support for the Core Institutes for iPS cell research from the Japanese Ministry of Education, Culture, Sports, Science and Technology (MEXT) to H.O. (JP25830055)

\section{Availability of data and materials}

All of the data generated and analyzed in this study are included in the published article.

\section{Author contributions}

YS, NK, TS, Michiko N, KT, YH, CI, M S, AM. and Minoru M performed experiments; NK, WA, NH, $\mathrm{HO}$ and Minoru N supervised the research; YS, NK and Minoru $\mathrm{N}$ wrote the manuscript. All authors read and approved the final manuscript.

\section{Ethics approval and consent to participate}

All of the experimental procedures for cell differentiation and analysis were approved by the respective Ethics Committees of Keio University School of Medicine (Approval Number: 20-16-28) and Hoshi University School of Medicine (Approval Number: 28-008).

\section{Consent for publication}

Written informed consent to publish was obtained from the patient and the healthy donor.

\section{Competing interests}

The authors declare that they have no competing interests.

\section{Publisher's Note}

Springer Nature remains neutral with regard to jurisdictional claims in published maps and institutional affiliations.

\section{Author details}

${ }^{1}$ Department of Pharmacology, Hoshi University School of Pharmacy and Pharmaceutical Sciences, Ebara, Shinagawa-ku, Tokyo 142-8501, Japan. ${ }^{2}$ Department of Physiology, Keio University School of Medicine, 35 Shinanomachi, Shinjuku-ku, Tokyo 160-8582, Japan. ' ${ }^{3}$ aboratory of Molecular Genetics, The Institute of Medical Science, The University of Tokyo, 4-6-1 Shirokanedai, Minato-ku, Tokyo 108-8639, Japan. ${ }^{4}$ Center for Genomic and Regenerative Medicine, Juntendo University, School of Medicine, Bunkyo-ku, Tokyo 113-8431, Japan. ${ }^{5}$ Department of Neurology, Juntendo University School of Medicine, Bunkyo, Tokyo 113-8421, Japan. 'Eife Science Tokyo Advanced Research Center (L-StaR), Hoshi University School of Pharmacy and Pharmaceutical Sciences, Ebara, Shinagawa-ku, Tokyo 142-8501, Japan.

Received: 14 November 2017 Accepted: 22 January 2018 Published online: 20 February 2018

\section{References}

1. Abbas N, Lücking CB, Ricard S, Dürr A, Bonifati V, De Michele G, Bouley S, Vaughan JR, Gasser T, Marconi R, et al. A wide variety of mutations in the parkin gene are responsible for autosomal recessive parkinsonism in Europe. French Parkinson's Disease Genetics Study Group and the European Consortium on Genetic Susceptibility in Parkinson's Disease. Hum Mol Genet. 1999:8:567-74.

2. Kitada $T$, Asakawa S, Hattori N, Matsumine H, Yamamura Y, Minoshima S, Yokochi M, Mizuno Y, Shimizu N. Mutations in the parkin gene cause autosomal recessive juvenile parkinsonism. Nature. 1998;392:605-8.

3. Dawson TM. Parkin and defective ubiquitination in Parkinson's disease. J Neural Transm Suppl. 2006:209-13.

4. Sulzer D. Multiple hit hypotheses for dopamine neuron loss in Parkinson's disease. Trends Neurosci. 2007;30:244-50.

5. Tanaka K, Suzuki T, Hattori N, Mizuno Y. Ubiquitin, proteasome and parkin Biochim Biophys Acta. 2004;1695:235-47.

6. Abizaid A, Liu ZW, Andrews ZB, Shanabrough M, Borok E, Elsworth JD, Roth $\mathrm{RH}$, Sleeman MW, Picciotto MR, Tschöp MH, et al. Ghrelin modulates the activity and synaptic input organization of midbrain dopamine neurons while promoting appetite. J Clin Invest. 2006;116:3229-39.

7. Diano S, Farr SA, Benoit SC, McNay EC, da Silva I, Horvath B, Gaskin FS, Nonaka N, Jaeger LB, Banks WA, et al. Ghrelin controls hippocampal spine synapse density and memory performance. Nat Neurosci. 2006;9:381-8.

8. Kojima M, Hosoda H, Date Y, Nakazato M, Matsuo H, Kangawa K. Ghrelin is a growth-hormone-releasing acylated peptide from stomach. Nature. 1999; 402:656-60.

9. Nakazato M, Murakami N, Date Y, Kojima M, Matsuo H, Kangawa K, Matsukura S. A role for ghrelin in the central regulation of feeding. Nature. 2001:409:194-8.

10. Cowley MA, Smith RG, Diano S, Tschöp M, Pronchuk N, Grove KL, Strasburger CJ, Bidlingmaier M, Esterman M, Heiman ML, et al. The distribution and mechanism of action of ghrelin in the CNS 
demonstrates a novel hypothalamic circuit regulating energy homeostasis. Neuron. 2003;37:649-61.

11. Andrews ZB, Erion D, Beiler R, Liu ZW, Abizaid A, Zigman J, Elsworth JD, Savitt JM, DiMarchi R, Tschoep M, et al. Ghrelin promotes and protects nigrostriatal dopamine function via a UCP2-dependent mitochondrial mechanism. J Neurosci. 2009;29:14057-65.

12. Osterstock G, Escobar P, Mitutsova V, Gouty-Colomer LA, Fontanaud P, Molino F, Fehrentz JA, Carmignac D, Martinez J, Guerineau NC, et al. Ghrelin stimulation of growth hormone-releasing hormone neurons is direct in the arcuate nucleus. PLoS One. 2010;5:e9159.

13. Shi L, Bian X, Qu Z, Ma Z, Zhou Y, Wang K, Jiang H, Xie J. Peptide hormone ghrelin enhances neuronal excitability by inhibition of Kv7/KCNQ channels. Nat Commun. 2013:4:1435.

14. Takahashi K, Tanabe K, Ohnuki M, Narita M, Ichisaka T, Tomoda K, Yamanaka S. Induction of pluripotent stem cells from adult human fibroblasts by defined factors. Cell. 2007;131:861-72.

15. Imaizumi Y, Okada Y, Akamatsu W, Koike M, Kuzumaki N, Hayakawa H, Nihira T, Kobayashi T, Ohyama M, Sato S, et al. Mitochondrial dysfunction associated with increased oxidative stress and a-synuclein accumulation in PARK2 IPSCderived neurons and postmortem brain tissue. Mol Brain. 2012;5:35.

16. Matsumoto T, Fujimori K, Andoh-Noda T, Ando T, Kuzumaki N, Toyoshima M, Tada H, Imaizumi K, Ishikawa M, Yamaguchi R, et al. Functional neurons generated from T cell-derived induced pluripotent stem cells for neurological disease modeling. Stem Cell Reports. 2016;6:422-35.

17. Imaizumi K, Sone T, Ibata K, Fujimori K, Yuzaki M, Akamatsu W, Okano H. Controlling the regional identity of hPSC-derived neurons to uncover neuronal subtype specificity of neurological disease phenotypes. Stem Cell Reports. 2015;5:1010-22.

18. Fujimori K, Matsumoto T, Kisa F, Hattori N, Okano H, Akamatsu W: Escape from Pluripotency via Inhibition of TGF-B/BMP and Activation of Wnt Signaling Accelerates Differentiation and Aging in hPSC Progeny Cells. vol. 9. pp. 1-17. Stem Cell Reports; 2017:1-17.

19. TJ HALEY, WG MCCORMICK. Pharmacological effects produced by intracerebral injection of drugs in the conscious mouse. Br J Pharmacol Chemother. 1957:12:12-5.

20. Suzuki S, Akamatsu W, Kisa F, Sone T, Ishikawa KI, Kuzumaki N, Katayama H, Miyawaki A, Hattori N, Okano H. Efficient induction of dopaminergic neuron differentiation from induced pluripotent stem cells reveals impaired mitophagy in PARK2 neurons. Biochem Biophys Res Commun. 2017:483:88-93.

21. Okano H, Yamanaka S. iPS cell technologies: significance and applications to CNS regeneration and disease. Mol Brain. 2014;7:22.

22. Howard AD, Feighner SD, Cully DF, Arena JP, Liberator PA, Rosenblum Cl, Hamelin M, Hreniuk DL, Palyha OC, Anderson J, et al. A receptor in pituitary and hypothalamus that functions in growth hormone release. Science. 1996;273:974-7.

23. Zigman JM, Jones JE, Lee CE, Saper CB, Elmquist JK. Expression of ghrelin receptor mRNA in the rat and the mouse brain. J Comp Neurol. 2006;494: $528-48$

24. Jiang H, Li LJ, Wang J, Xie JX. Ghrelin antagonizes MPTP-induced neurotoxicity to the dopaminergic neurons in mouse substantia nigra. Exp Neurol. 2008;212:532-7.

25. Moon M, Kim HG, Hwang L, Seo JH, Kim S, Hwang S, Lee D, Chung H, Oh MS, Lee KT, Park S. Neuroprotective effect of ghrelin in the 1-methyl-4phenyl-1,2,3,6-tetrahydropyridine mouse model of Parkinson's disease by blocking microglial activation. Neurotox Res. 2009;15:332-47.

26. Albarran-Zeckler RG, Brantley AF, Smith RG. Growth hormone secretagogue receptor (GHS-R1a) knockout mice exhibit improved spatial memory and deficits in contextual memory. Behav Brain Res. 2012;232:13-9.

27. Shin JH, Ko HS, Kang H, Lee Y, Lee Yl, Pletinkova O, Troconso JC, Dawson VL, Dawson TM. PARIS (ZNF746) repression of PGC-1a contributes to neurodegeneration in Parkinson's disease. Cell. 2011;144:689-702.

28. Jiang $H$, Kang SU, Zhang S, Karuppagounder S, Xu J, Lee YK, Kang BG, Lee $Y$, Zhang J, Pletnikova O, et al. Adult conditional knockout of PGC-1a leads to loss of dopamine neurons. eNeuro. 2016;3

\section{Submit your next manuscript to BioMed Central and we will help you at every step:}

- We accept pre-submission inquiries

- Our selector tool helps you to find the most relevant journal

- We provide round the clock customer support

- Convenient online submission

- Thorough peer review

- Inclusion in PubMed and all major indexing services

- Maximum visibility for your research

Submit your manuscript at www.biomedcentral.com/submit
Biomed Central 